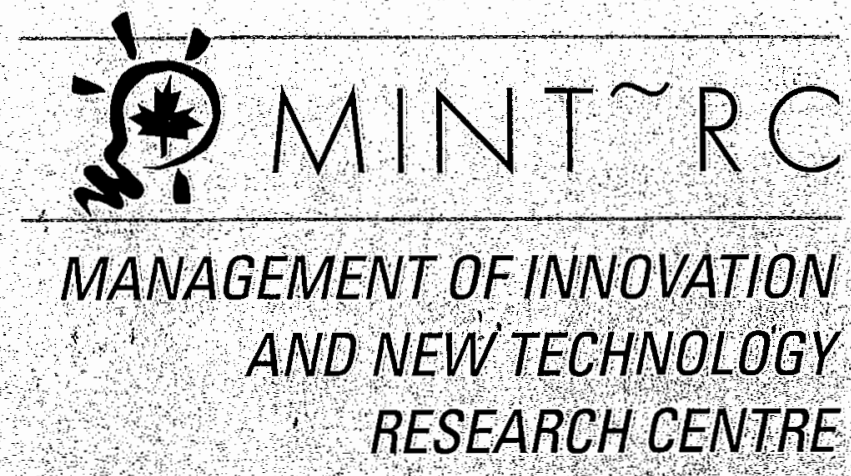

E-IMPROVISATION: COLLABORATIVE GROUPWARE TECHNOLOGY EXPANDS THE REACH AND EFFECTIVENESS OF ORGANIZATIONAL IMPROVISATION

by

Brent McKnight

Management of Innovation and New Technology Research Centre

WORKING PAPER NO. 104 June 2001

Innis

Bisis

HD

45

. .W657

no.104

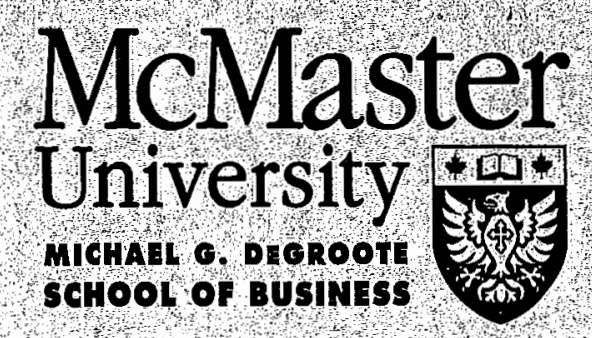




\title{
E-IMPROVISATION: COLLABORATIVE GROUPWARE TECHNOLOGY EXPANDS THE REACH AND EFFECTIVENESS OF ORGANIZATIONAL IMPROVISATION
}

\author{
by \\ Brent McKnight \\ Management of Innovation and New Technology \\ Research Centre \\ WORKING PAPER NO. 104 \\ June 2001
}

The Working Paper series is intended as a means whereby a researcher may communicate his or her thoughts and findings to interested readers for their comments. The paper should be considered preliminary in nature and may require substantial revision. Accordingly, this Working Paper should not be quoted nor the data referred to without the written consent of the author. Your comments and suggestions are welcome and should be directed to the author. 


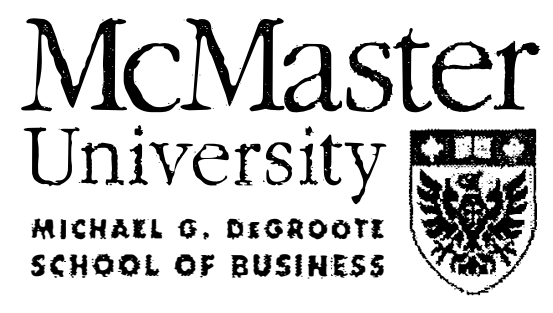

\title{
E-Improvisation: Collaborative Groupware Technology Expands the Reach and Effectiveness of Organizational Improvisation
}

\author{
Brent McKnight \\ Research Associate \\ DeGroote Business School, McMaster University \\ Hamilton, Ontario, Canada \\ mcbrentca@yahoo.ca
}




\title{
E-Improvisation: Collaborative Groupware Technology Expands the Reach and Effectiveness of Organizational Improvisation
}

\begin{abstract}
With today's increasing pace of change, managers who are struggling to continuously adapt and survive are turning to an emerging management technique known as organizational improvisation. This field of management science draws from a metaphor based in improvisational theatre and jazz music and is defined as: "The ability to spontaneously recombine knowledge, processes and structure in real time, resulting in creative problem solving that is grounded in the realities of the moment."

As part of these changes, organizations are working across great distances and in groups that include diverse constituents such as suppliers, partners and customers. The distance separating these team members poses a problem for improvisation as improvisation relies heavily on interpersonal communication between group members. The collaborative wealth of creativity, innovation and productivity flows in part from this real-time interaction. The increasing distance between group members hampers the effective reach of organizational improvisation.

The proposed concept of e-Improvisation suggests that the adoption of groupware collaborative software, in particular a peer to peer offering called Groove, can extend the reach of improvisation and enhance it's effectiveness.
\end{abstract}

\section{BIO: Brent McKnight}

Brent McKnight graduated with a Bachelor of Computer Engineering and Management from McMaster University in June, 2001. During his time at McMaster he founded the Inane Asylum Performance Improvisation Team and the McMaster Improvisation Club. Through these institutions he performed for more than 500 people, taught 10 classes on improvisational skills to business and engineering students and ran over 50 workshops teaching improvisation.

Brent begins work as a technology analyst for Accenture (formerly Andersen Consulting) in the fall of 2001 where he hopes to continue working with collaborative technologies and organizational improvisation.

Brent has been a research associate for Dr. Nick Bontis at McMaster University since the fall of 1999. He also worked as an intern for IBM Canada where he was part of a competitive intelligence team responsible for the competitiveness of IBM's personal computer and server product line. In addition to the responsibilities of monitoring IBM's competitiveness, Brent initiated a project to examine how IBM could better leverage news sources as well as access the knowledge present in IBM's sales force.

As practitioner recruitment director for the McMaster World Congress on Electronic Commerce and Intellectual Capital Brent recruited more than 30 speakers. The event was host to more than 500 practitioners, academics and students from over 33 different countries. 
"The $21^{\text {st }}$ century will be about velocity: The speed of business and the speed of change."

Bill Gates, Author of Business at the Speed of Thought

\section{Introduction}

Today's business world is evolving at an accelerated pace and companies are faced with the reality that there is not always time to plan. A management science that tackles this problem and allows organizations to adapt to this rapid rate of change is emerging. Organizational improvisation is based on lessons learned from examining improvisational theatre and jazz music and applying the metaphor to the way an organization functions.

Improvisation results in innovative problem solving, a convergence of planning and action, increased flexibility in response to changing external and internal stimuli, and increased team and employee satisfaction. These are valuable results and makes organizational improvisation an appealing field of study.

There are challenges however to the implementation of organizational improvisation. Traditional improvisation, in theatre for instance, takes place through face-to-face communication where improvisers are capable of expressing ideas and emotions using a wide range of communication channels in real-time. In part, it is this intensity of communication that allows improvisation to function properly. Employees, however, are often working at great distances from each other posing significant problems and hampering the effective reach of improvisation.

In addition, improvisation is an art that builds on existing ideas, jazz musician Charles Mingus insists “you can't improvise on nothing; you've gotta improvise on something” 
(Kemfeld, 1995:119). In the same way, organizational improvisation builds on the ideas, processes, and business strengths of a company. A lack of information or the presence of incorrect information can induce outcomes that aren't consistent with current business realities. The challenge of accessing correct information in a timely manner is growing more difficult as knowledge is predicted to double every 11 hours as early as the year 2010 (Bontis, 2001:1). This fast pace is heightening the problem and impacting the effectiveness of improvisation.

In this paper, the concept of e-improvisation is proposed, suggesting the adoption of groupware applications to empower employees to improvise. Emerging collaborative groupware technologies expand the reach and enhance the effectiveness of organizational improvisation by allowing employees to continuously interact in a robust communication environment and access important knowledge in a timely manner.

\section{Organizational Improvisation}

A close look at the roots of organizational improvisation, jazz music and improvisational theatre, reveal that although they are different in many ways, at the heart of each is the same skill set that interests management theorists. This skill set embodies adaptability, spontaneity, teamwork and collaboration skills.

Jazz music originated in New Orleans, USA, around the mid-1890's. Improvisational jazz musicians use melody ideas or chord sequences as focal points around which they 
collectively create a song. Musicians work together resulting in a performance that is an emergence of the collective (Hatch, 1999).

Improvisational theatre first appeared in 16th century Italy as performed by the Commedia Dell'Arte. Traveling troupes of actors worked with stock characters and basic plot premises, constructing scenes in response to their fellow actors and audience reaction. Although the Commedia Dell'Arte style is considered to have died out in the early $18^{\text {th }}$ century (Geisinger, 1971) the art was modernized by Viola Spolin (Viola Spolin, 1963) as a training and development method for traditional theatre actors.

Organizational improvisation has been defined in many ways. Appendix A contains select definitions as reported by Vera (2000) and Cunha, Cunha and Kamoche (2000). The following definition is offered as a combination of those selected: "The ability to spontaneously recombine knowledge, processes and structure in real time, resulting in creative problem solving that is grounded in the realities of the moment."

Regardless of the definition used, improvisation is characterized by the process through which it operates. Improvisers leverage a set of unique teamwork skills and rules in the performance of improvisation. These rules require participants to build on, not block, the ideas of the team members through a process improvisers call "yes and-ing". In addition, the leadership of the improvisational team is dynamic and fluid as different members give and take leadership. The result is a strategy that is an emergent of the collective group (Crossan, 1997). 
Organizations cannot continuously improvise without planning as well. Improvisation exists to fill the gap between that which is planned and that which is required. Through effective planning, this gap can be reduced, leaving less for improvisation to have to fill (Sharkansky and Zalmanovitch, 2000:4).

Cunha, Cunha and Kamoche (2000) and Vera (2000) successfully review the literature by integrating the ideas of many and in doing, provide the foundation for continued research. This paper does not seek to replicate this work, but leverage off it by introducing improvisation-enhancing groupware technology to better the science of organizational improvisation.

\section{Groupware Technology}

The growth and development of the telecommunications industry is introducing fantastic new communication applications. Some of these applications are drastically changing the way we can communicate in groups. Complexity theorist Brian Arthur says:

The Web provides access to the stored memories, the stored experiences of others. And that's what is also particular to humans: our ability not just to think and experience but to store our thoughts and experiences and share them with others as needed, in an interactive culture. What gives us power as humans is not our minds but the ability to share our minds, the ability to compute in parallel. And it's this sharing this parallelism - that gives the Web its power. (Homer-Dixon, 2000:307)

The Internet and its capability for collaboration are emerging. This next section discusses a class of collaborative software tools called groupware. 
Groupware technologies are designed to allow users to communicate more effectively, improve productivity at meetings, provide access to knowledge repositories, and/or manage projects. These systems are currently, for the most part, single purpose applications designed for specific tasks (meetings, project management, communication, or knowledge management), however there is a convergence towards more robust and generalized communication systems as the recognition of their return on investment is realized.

The new systems that are evolving will combine project management tools (for meeting/event scheduling and milestone management), real time voice/chat/video communication tools, meeting productivity tools (for opinion polling, anonymous brainstorming, and shared solution generation), and knowledge management tools (to create, maintain and access information from both internal and external sources).

These groupware applications are offered across three main Internet technologies: the World Wide Web, corporate intranets/extranets and peer-to-peer (P2P) networks. Although each of these technologies can be used to build applications that support teamwork, collaboration and even improvisation, P2P networking lends itself particularly well to the task due to it's decentralized nature. P2P networking has recently been brought to widespread public attention through the online music sharing efforts of Napster. Napster allows users to share music files that are stored on their machines around the world. Computers in P2P networks communicate directly with each other without the need for centralized control. Appendix B shows the difference between 
computers connected in a P2P fashion and those connected in a centralized manner. Groove (www.groovenetworks.com) and Napster (www.napster.com) are good examples of P2P applications.

The decentralized nature of $\mathrm{P} 2 \mathrm{P}$ means that self-organizing teams can form spontaneously without the need for a central organizing server. They form out of the common need to solve a problem or complete a project and can disband just as quickly. Groove is an application that is emerging as a powerful tool for facilitating virtual teams.

\section{Groove}

Groove was launched at the beginning of April 2001 by Ray Ozzie, creator of Lotus Notes, and seems to have been written with improvisation in mind. The creator of the software has drawn the parallel himself stating that "Groove works like a jazz band. It's intended for people who want to get together and jam - to interact and improvise with each other" (Breen, 2001).

Groove provides for the integration of all the features that single-function groupware systems aim to satisfy. Users form shared groove workspaces where they are able to engage in real-time text and voice chat, create and edit a wide variety of documents together, manage project progress information, engage in discussion groups, share files, access data from competitive intelligence and enterprise resource planning (ERP) databases, and browse the Web together. Groove is designed as a platform and uses third party "Groove tools" that can be built and tailored to an organization's specific 
requirements. These tools are installed at the time of need, Appendix $\mathrm{C}$, as the need arises. Examples of possible tools include:

- Video conferencing to display real-time video of each online team member.

- Specialized viewers and editors to enable collaborative creation of building blueprints, CAD documents, software programs and web-sites.

- Project management tools to manage timelines, due dates and responsibilities.

- And productivity tools for anonymous brainstorming and idea selection as well as argument resolution.

The ways in which Groove users communicate and collaborate are limited only by the imagination of Groove tool developers.

Each member of a Groove space stores a copy of the group's files, chat logs, and discussions. As members modify files and discussion forums, changes are transmitted to all the members of the Groove space. Because the information is stored on each member's computer, changes made when a user is offline are both transmitted and received when the offline user logs back on. Appendix D shows a Groove file repository

Groove provides a technological tool that is designed to be diverse and powerful: To demonstrate it's ability to enhance organizational improvisation, Vera's model consisting of six moderating variables will be reviewed. The moderating variables proposed by Vera (2000) on improvisation and group performance are: (1) real-time information and communication, (2) organizational memory, (3) culture, (4) environmental turbulence, (5) teamwork skills, and (6) individual expertise and skill. The first four are proposed as necessary for improvisation, while the last two exist to improve or moderate the quality of the improvisational performance. All six variables can vary in the degree that they are present, affecting the level and quality of the improvisation that occurs. 
The first three variables, real-time communication, organizational memory and organizational culture, are highly relevant with regards to the use of groupware technologies. Groove's ability to improve organizational improvisation will be discussed with respect to these variables. The final three variables, environmental turbulence, teamwork and individual expertise, although important to improvisation are not examined with respect to groupware. Environmental turbulence refers to changes in the market, in technology and in the organization itself. Teamwork skills cover a range of special improvisational abilities and individual expertise is the knowledge that employees have and can bring to bear to solve problems.

\section{Groove Enhances Real-Time Communication}

Real-time communication is proposed by Vera as a moderating variable of improvisation. It is defined as “information about a firm's operations or environment for which there is little or no time lag between occurrence and reporting"(Vera, 2000:30). This information can take the form of news and market information or, as will be discussed in this section, the real-time interaction between employees.

Face-to-face, employees have a wide range of communication mediums to use. These include verbal language, body movements, facial expressions, and even choice of clothing and style. As a result, a significant amount of information is conveyed in addition to words. Traditionally, employees working at distances had available limited communication tools such as the telephone, email, chat rooms, and occasionally video 
conferencing. Individually these technologies may not provide the richness of communication required for improvisation to occur. The challenge is to capture in groupware as many elements of human communication as possible. Groove opens up many of the communication and collaboration mediums available in face-to-face meetings, offers some new mediums and holds promise for continued development.

When Ray Ozzie began designing Groove, he started by examining the sociology behind how people interact and identified 20 dimensions of human interaction. These included how we communicate emotions, visual items, and with people in different time zones. He then challenged himself to build a technology that allowed a full variety of human interaction (Breen, 2001). In addition to voice and text chat, instant messaging, file exchange, and lagged-time discussion boards users of Groove are able to benefit from collaboratively creating and editing documents in real-time, navigating web spaces and file repositories together, and sharing version controlled file repositories that are generated specifically for and by each group. In Appendix E a business plan is being collaboratively created.

Groove is designed to be an "always on" application. Users work at their desks and contact is maintained with all members of the group. While at their desks, employees have access to the phones, peripherals, paper documents and other tools that are still required for work to get done. In essence, although individuals cannot touch each other and may miss out on some of the more subtle nuances of communication, their real-time communication is sustained as they work. 
There are currently serious limitations on the ways humans interact with computers that pose restrictions on the quality of real-time communication that can occur. Users are limited to a keyboard and a mouse for input and a monitor and speakers for output. To develop this human-machine interaction the increased use of writing tablets, touch screen monitors, voice recognition, video input, and even far-fetched technologies to transfer subtle human pheromones between users should be explored. By enhancing the humanmachine interface we allow for even greater human-human communication through groupware.

While team members are still not able to touch and smell each other and as a result subtle communications may be missed, Groove offers compelling real-time communication channels and some even more intriguing collaborative mediums. Groove succeeds in providing a sustained real-time communication channel that permits users to continuously interact in real-time from wherever they are.

\section{Groove Supports the Codification and Accessibility of Organizational Memory}

Organizational memory is the information stored in an organization's culture, procedures, and information technology tools. Organizational memory as it relates to improvisation has a paradoxical relationship; although greater degrees of memory will generate more effective improvisation, improvisation is less likely to occur as employees will tend to rely on existing solutions and procedures. Moorman and Miner (1998:8) break organizational memory into two components; procedural and declarative memories. Procedural memories involve skills, routines, and cultural norms that are learned by 
employees. Declarative memory are facts such as competitive intelligence and market realities.

Groupware technologies can provide quick and timely access to organizational memory both procedural and declarative. Within a shared Groove workspace participants create chat logs, sketches, and notes and bring files from external sources into a workspace file repository. This pool of data or memory is geared specifically to each group and grows as the project develops and progresses. In addition, organizations are increasingly accumulating and leveraging databases of competitive intelligence, news, product specifications, customer information and peer experience to gain competitive advantage. Tools built for use with Groove can access these data stores thereby significantly expanding available organizational memory.

Knowledge, both from past experiences as well as current ones, provide the impetus for improvisation to occur. David Gendron, Compaq Canada has identified that "decentralized decision-making and empowerment initiatives have shifted much of the decision making from executive levels to the rank and file to enable employees to directly and effectively deal with customer and process issues. This creates a need for immediate knowledge that, often, must cross functions and transcend hierarchies." (Gendron, 2001) More important than the basic requirement for this knowledge is the need for it to be accurate, complete and timely. The collective knowledge must be a good enough approximation of the true environment in which the organization is operating so that improvising employees can respond correctly. 
A knowledge management system that actively searches for knowledge that employees need, delivers it to them in the way it is needed, and does this just as it is needed should be able to significantly enhance the effectiveness of improvisation. The use of effective knowledge management addresses the combined need for competitive and market organizational memory with the need for this information to be delivered in real-time. By adding tools to Groove that push relevant information to the improvisers, more effective improvisation can result.

\section{Groove Empowers a Collaborative Culture}

An improvising organization must be tolerant of experimentation and errors, provide for continuous leaming from these experiences, and empower employees to take spontaneous action(Vera, 2000:35; Crossan, 1997:3). This is not an easy task but it's successful adoption can be assisted by the adoption of groupware, and in particular, by Groove.

Improvisers are continuously experimenting by recombining knowledge and procedures in new ways. They learn from both their successes and their failures and it is important that employees are rewarded for this risk-taking and for competent experimentation(Vera, 2000:35). As an improviser learns, greater skill and information can be leveraged in future situations resulting in more effective improvisation. Organizations whose cultures encourage leaming are called knowledge centric or inquiring organizations. "Developing an inquiring organization involves building a community of minds, fostering effective dialogue, avoiding bureaucracy, occasionally rocking the boat and reinventing the organization, and building a storehouse of knowledge, that is, a knowledge management 
system." (Courtney et al., 2000:141) It is evident that these qualities are very similar to those needed for an improvisational culture. Stressed are wide information distribution, shared responsibilities, less structured management, and continuous learning with a willingness to take risks. By training employees of knowledge centric organizations with improvisational skills an organization should be able to improvise effectively.

Improvisation is spontaneous, action and analysis converged, requiring employees to have the ability to take action. Employees must be empowered with the proper tools, resources and knowledge to make the analysis and take the action required within a very short time frame. The very nature of Groove's peer to peer architecture means that teams are empowered with communication tools, with access to the expertise of their groups, and most importantly with knowledge. The knowledge that users of Groove have access to is created by the group itself and brought in from the edges of the organization. Although for employees to be empowered to improvise properly the organization must truly value the freedom it has provided, the adoption of Groove can help organizations enable employees to act spontaneously.

\section{Conclusion}

Groove offers a number of ways to improve the effectiveness of organizational improvisation. The use of Groove increases the real-time communication between group members by connecting the team for the duration of the work day. It also provides access to the group specific organizational memory located within Groove workspaces as well as that found in corporate data-stores. This knowledge is provided in real-time to 
employees as they need it. Finally employees are empowered to work and collaborate together due to Groove's decentralized nature. In addition to this increase in the effectiveness of improvisation, the ability to improvise is extended to employees working at great distances from each other.

Knowledge management plays a central role as it assists in implementing the proper culture and enhances real-time communication by providing knowledge to employees on a timely basis. Further development in the use of software tools at the intersection of knowledge management and improvisation holds great promise for improvising managers. It is early however in the adoption of groupware and Groove and the evidence is not clear. With greater adoption of groupware, it's effects on organizational improvisation can be examined more thoroughly. 


\section{Appendix A}

\begin{tabular}{l|l}
\multicolumn{1}{c|}{ Author } & \multicolumn{1}{c}{ Definition } \\
\hline Miner et al., 1996 & $\begin{array}{l}\text { "...actions, both spontaneous and novel, that result in the creation of } \\
\text { something while actions are unfolding." }\end{array}$ \\
\hline Ciborra, 1996 & $\begin{array}{l}\text { "...efficiently generate new combinations of resources, routines and } \\
\text { structures which are able to match the present, turbulent } \\
\text { circumstances." }\end{array}$ \\
\hline Hatch, 1997 & $\begin{array}{l}\text { "...intuition guiding action upon something in a spontaneous but } \\
\text { historically contextualized way." }\end{array}$ \\
\hline Vera, 2000 & $\begin{array}{l}\text { "...the ability to engage in a spontaneous process of creative thought } \\
\text { or action." }\end{array}$
\end{tabular}

Sources: Cunha, Cunha and Kamoche, 2000; Vera, 2000

Appendix B: Centralized vs. Decentralized Networks

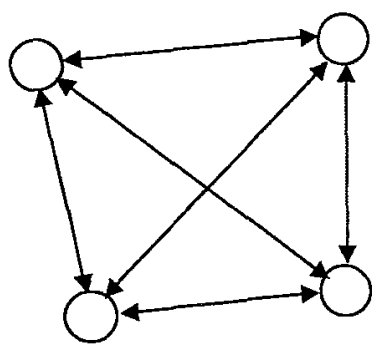

Decentralized Network

(Peer to Peer)

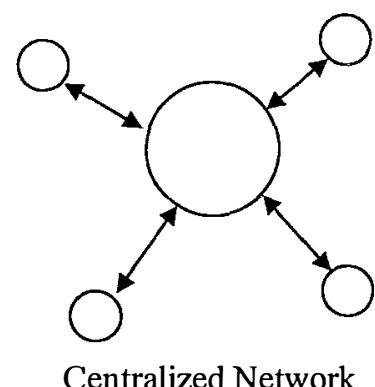

(Web-based, Intranet) 


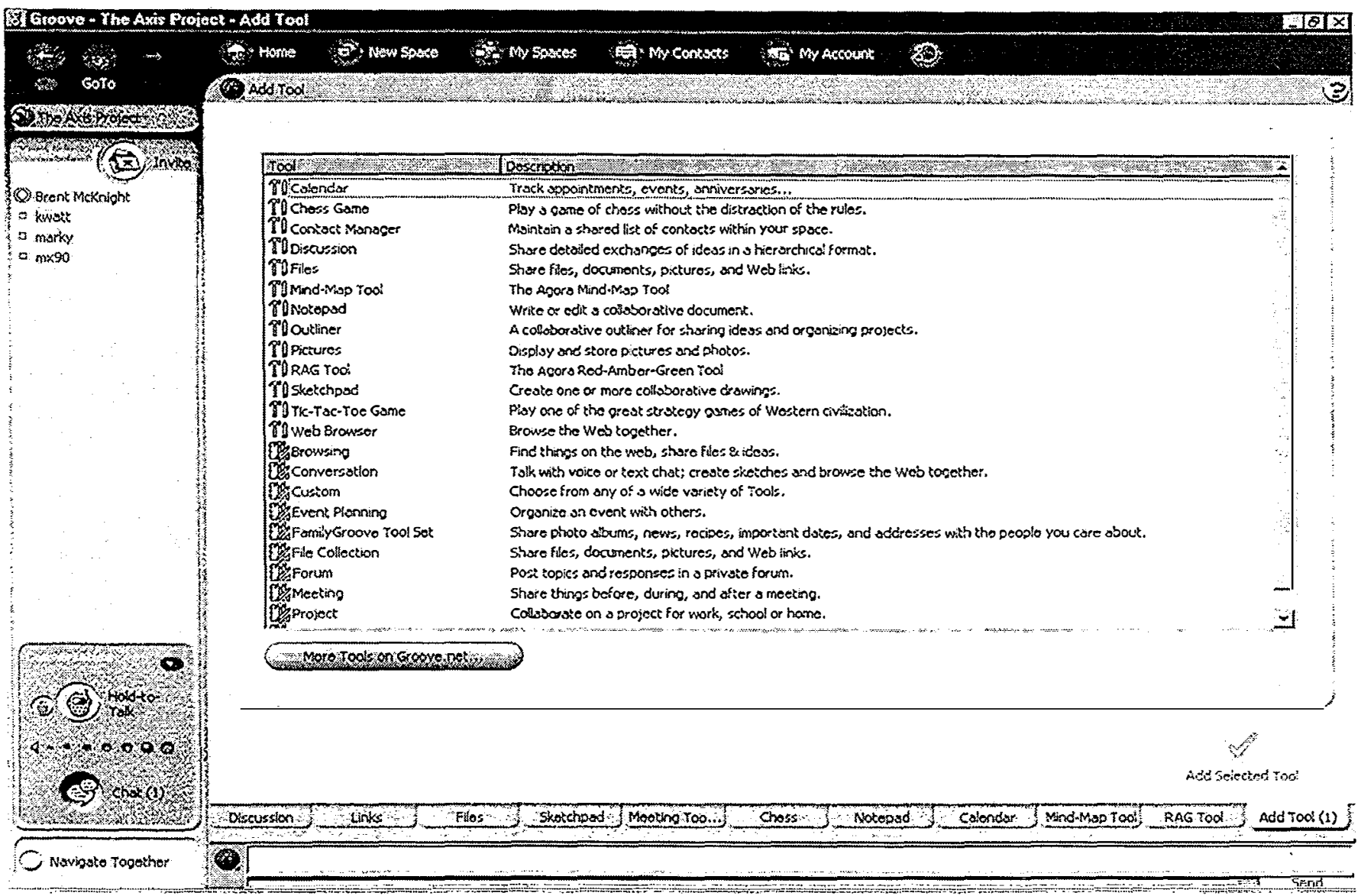

Appendix C: Add a new tool to a shared Groove workspace

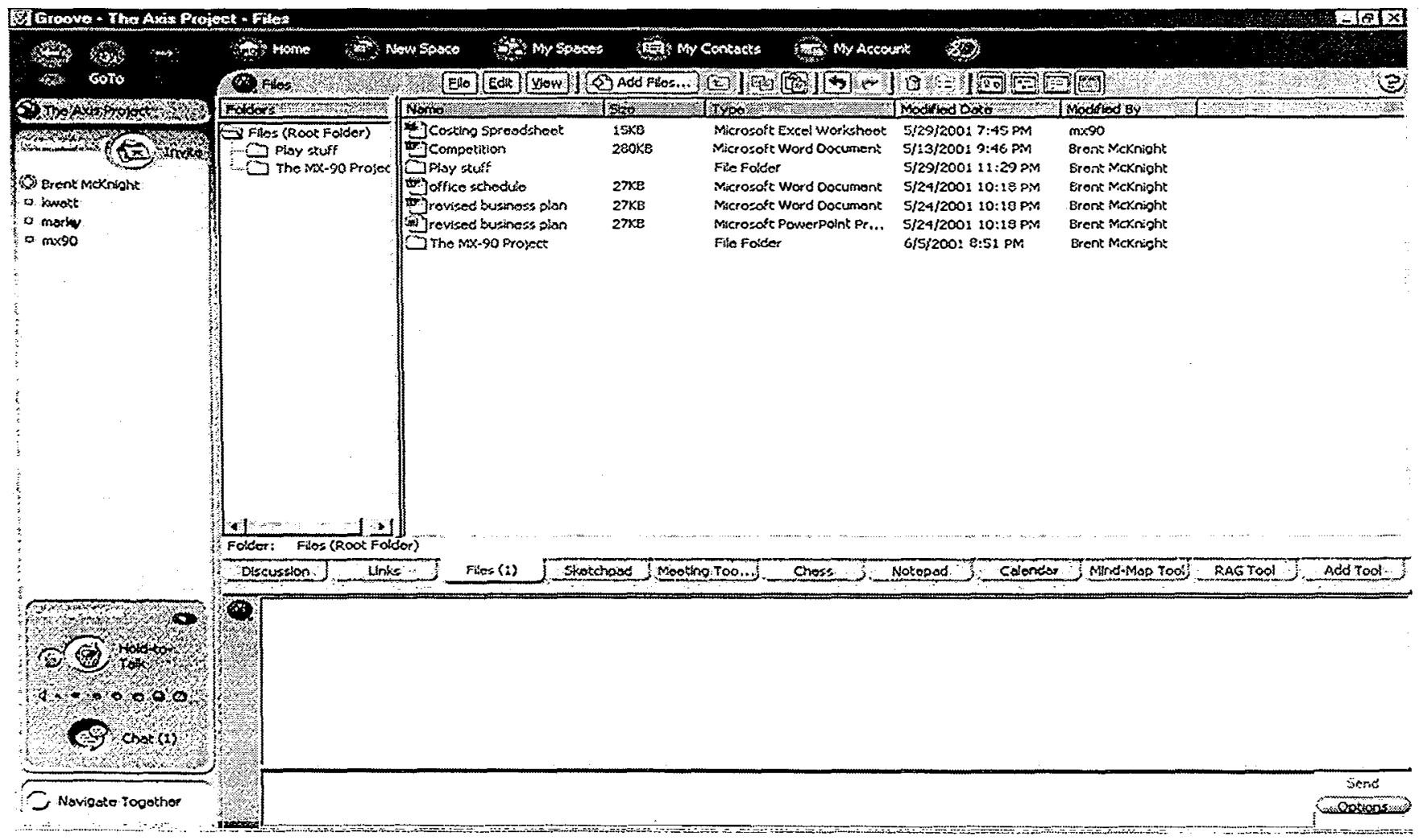

Appendix D: A file repository where files and documents are stored 


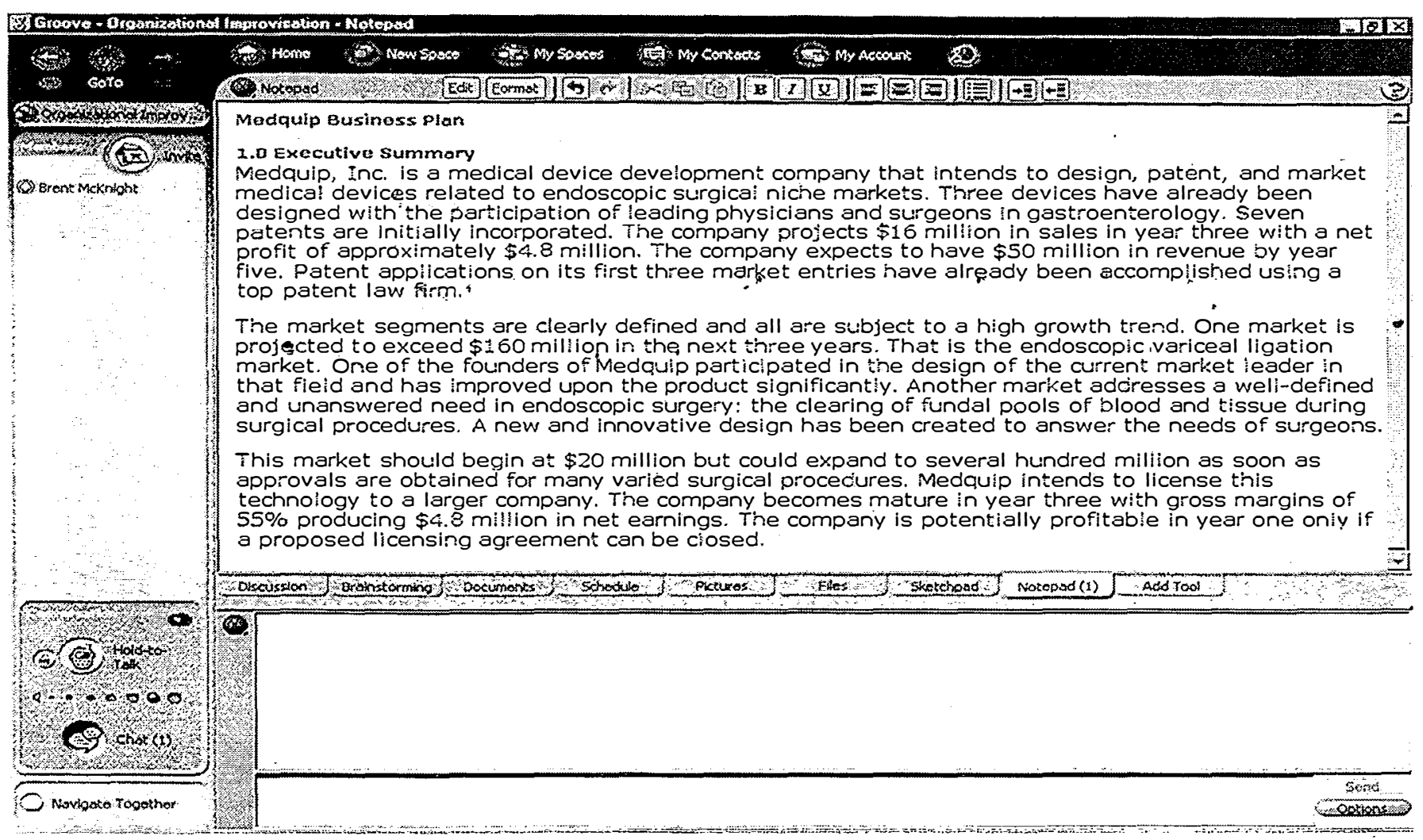

Appendix E: A business plan being created by team members.

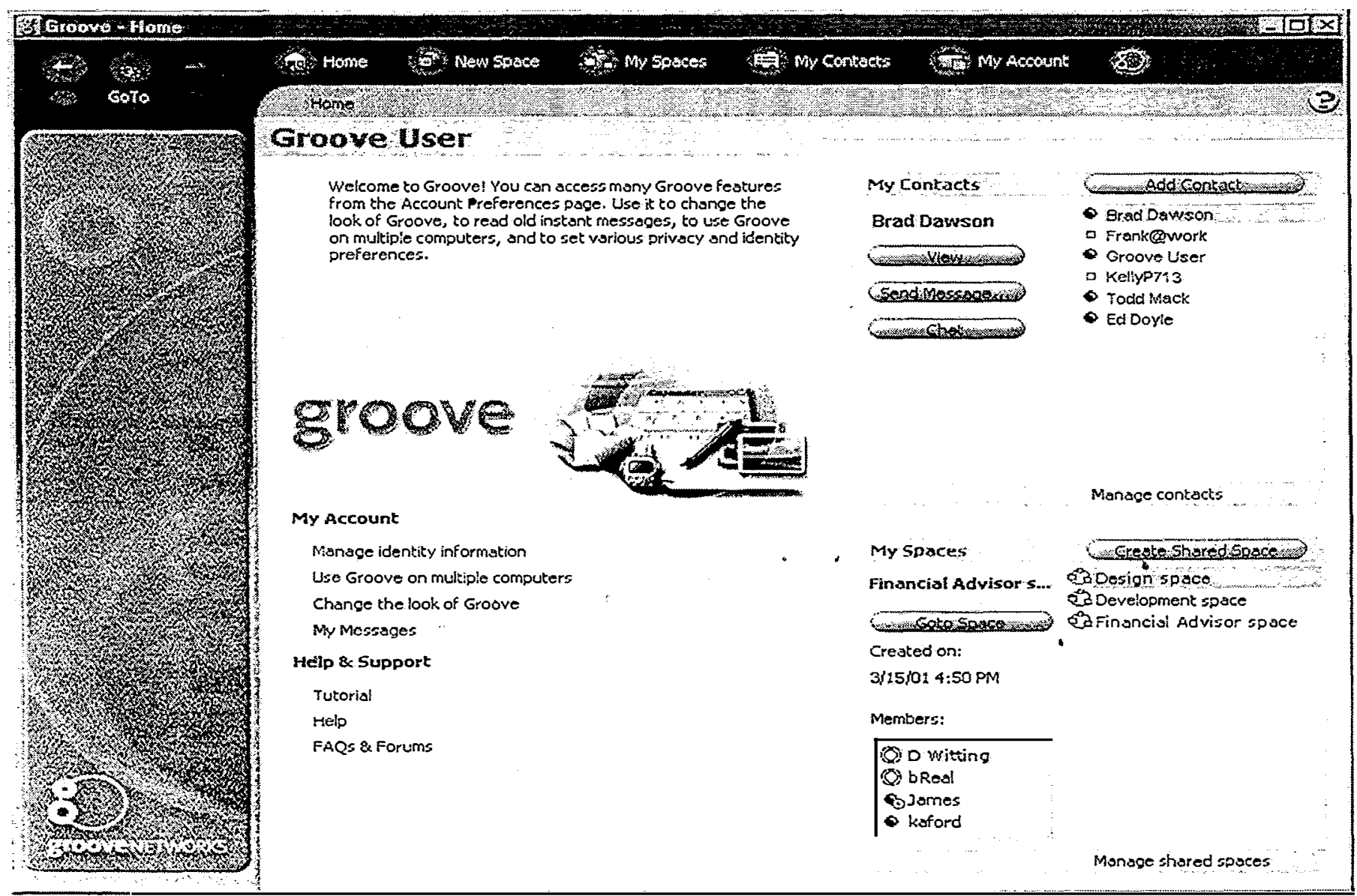

Appendix F: See who is online and visit a shared workspace 


\section{References}

Bontis, Nick (2001). Assessing Knowledge Assets: A review of the models used to measure intellectual capital, International Journal of Management Reviews, 3, 1, 41-60.

Borthick, Sandra. Reaching into today's collaborative toolkit. Business Communications Review.

Breen, Bill (2001). Jazzed About Work. Fast Company. Issue 46, 192.

Brown and Eisenhardt (1997). The art of continuous change: Linking complexity theory and time-paced evolution in relentlessly shifting organizations. Administrative Science Quarterly. Vol. 42, Issue \#1

Ciborra, C.U. (1996). The platform organization: Recombining strategies, structures and surprises. Organization Science, 7(2), 103-118.

Courtney et al. (2000) Developing Inquiring Developing Inquiring Organizations.

Knowledge Management Consortium International, 1, 1, 141

Crossan (1997). Improvise to Innovate. Ivey Business Joumal. Vol. 62, Issue \#1.

Cunha, Cunha and Kamoche (2001). Organizational Improvisation: What, When, How and Why. Working Paper.

Gates, Bill, Business at the Speed of Thought. 1999, Time Warner Company, New York.

Gendron (2001). Right Time, Right Place. Ideas. May.

Geisinger, Marion, Plays Players and Playwrights. 1971, Hart Publishing Company, New York.

Hatch, Mary Jo, (1999). Exploring the Empty Spaces of Organizing: How Improvisational Jazz Helps Redescribe Organizational Structure. Organizational Studies, Wntr.

Hatch, M.J. (1997). Jazzing up the theory of organizational Improvisation. Advances in Strategic Management, 14, 181-191.

Johnson, B. M., \& Rice, R.E. (1984). Reinvention in the innovation process: The case of word processing. In R.E. Rice (Ed.), The new media (pp. 157-183). Beverly'Hills: Sage.

Kernfield, B. 1995. What to Listen for in Jazz. Yale Univ., New Haven, CT.

Miner, A., Moorman, C. \& Bassoff, P. (1996). Organizational improvisation in new product development. 
Miner and Moorman (1998). Organizational improvisation and organizational memory. The Academy of Management Review. Vol. 23, Issue 4.

Moorman, C., \& Miner, A. (1998a). The convergence between planning and execution: Improvisation in new product development. Journal of Marketing, 62 1-20.

Process Edge, http://www.processedge.com/store/paperculture/whitepaperkmculture2.htm, , March $31^{\text {st }}$

Shani, et al. (2000). Knowledge work teams and groupware technology. Journal of Knowledge Management. Vol 4, Issue 2.

Sharkansky, Ira and Yair Zalmanovitch (2000). Improvisation in public administration and policy making in Israel. Public Administration Review. Jul/Aug.

Vera, Dusya (2000). Improvisation and its impact on group performance: A quasiexperiment. Thesis Proposal, Richard Ivey School of Business, University of Western Ontario.

Spolin, Viola. Improvisation for the Theater. 1999, Northwestern University Press, Illinois.

Warkentin et al. (2001). E-knowledge networks for inter-organizational collaborative ebusiness. Logistics Information Management. Vol. 14.

Yen et al. (1999). Groupware: a strategic analysis and implementation. Industrial Management \& Data Systems. 
Jnnis

REF HD

45

. W657 no. 104 
The activities of the Management of Innovation and New Technology Research Centre are generously supported by:

- The DeGroote family

- DuPont Canada Inc

- Nórtel

- Royal Bank

- The Society of Management Accountants of Ontario

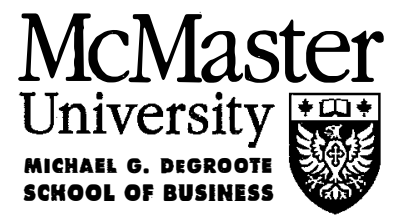

INFORMATION...

For information about the Management of Innovation and New Technology Research Centre or innovation research activities at the Michael G. DeGroote School of Business:

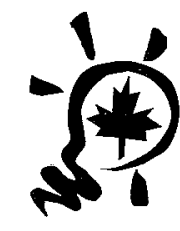

Director; Dr. C. K. Bart, Ph.D., C.A.

MINT - Research Centre

Michael G. DeGroote School of Business

McMaster University, 1280 Main St. W.

Hamilton ON Canada L8S 4M4

Phone: 905-525-9140, Ext. 24105

Fax: $905-521-8995$

email: mint@mcmaster.ca

www: http://mint.mcmaster.ca/

*Management of Innovation and New Technology Research Centre (MINT) is an official mark of the

Michael G. DeGroote School of Business,

McMaster University. 